\title{
Reduced hepcidin level features osteoporosis
}

\author{
BIN LIU ${ }^{1 *}$, CAIHUA LIU ${ }^{2 *}$, WEIFENG ZHONG ${ }^{3}$, MIN SONG $^{4}$, SHOUQIN DU $^{5}$ and JIANLI SU ${ }^{6}$ \\ ${ }^{1}$ Department of Nuclear Medicine, The Affiliated Hospital of Qingdao University, Qingdao, Shandong 266003; \\ ${ }^{2}$ Department of Laboratory Medicine, People's Hospital of Qingdao Shibei District, Qingdao, Shandong 266033; \\ Departments of ${ }^{3}$ Hospital Infection Management, ${ }^{4}$ Dermatoloogy, and ${ }^{5}$ Laboratory Medicine, \\ People's Hospital of Zhangqiu District, Jinan, Shandong 250200; ${ }^{6}$ Department of Laboratory Medicine, \\ Qilu Hospital of Shandong University (Qingdao), Qingdao, Shandong 266035, P.R. China
}

Received December 14, 2017; Accepted June 15, 2018

DOI: $10.3892 / \mathrm{etm} .2018 .6410$

\begin{abstract}
Osteoporosis (OP) is a common serious skeletal disorder marked by increased risk of bone fracture due to fragility. OP has been taken to be a disease linked with abnormal calcium metabolism that alone is obviously insufficient to explain the development of OP. Iron overload has been associated with the development of OP and increasing studies have suggested the association. However, direct evidence for this has not been clinically established. To this end, using the Roche biochemical autoanalyzer, we detected the concentration of iron, soluble transferrin receptor 2 (TFR2), and hepcidin, a key peptide regulating iron homeostasis, in the sera from patients with OP. It was shown that the iron and TFR2 concentration was markedly higher than that of healthy control; whereas the concentration of hepcidin was markedly lower than that in control. In addition, to pilot explore the underlying mechanism by which hepcidin was downregulated, we present that hepcidin can directly interact with TFR2 using immunoprecipitation. The present study first established the direct biochemical evidence for the involvement of hepcidin in the pathogenesis of OP, indicating that the upregulation of hepcidin could be used as a novel alternative therapeutic strategy in the management of OP.
\end{abstract}

\section{Introduction}

Osteoporosis (OP) is a common but serious skeletal disorder where increased bone weakness increases the risk of broken bone, especially for the older patients. OP is a major public health problem, and a serious economical burden for the patients (1). Although little is known about how OP develops,

Correspondence to: Dr Jianli Su, Department of Laboratory Medicine, Qilu Hospital of Shandong University (Qingdao), 758 Hefei Road, Shibei, Qingdao, Shandong 266035, P.R. China

E-mail: wln20081031@163.com

*Contributed equally

Key words: osteoporosis, iron, hepcidin, TFR2, ELISA numerous factors (2), including sex, genetics, age, hormones and diet, have been identified as being involved in the development of OP or identified to be able to increase the likelihood of OP.

OP has been considered to be a disease associated with abnormal calcium metabolism. Several lines of evidence supported the hypothesis $(3,4)$. Nonetheless, a growing number of clinical observations strongly suggest the association of iron overload with bone diseases, particularly with osteoporosis $(5,6)$. Therefore, elevated iron level has been suggested to be implicated in and has been linked to the risk factor of OP. Actually, the first clinical observation was made by Sinigaglia and colleagues (7) in patients with OP in the setting of genetic hemochromatosis. Although the observation was obviously somewhat compounded by the linkage between iron concentration and hemochromatosis in OP, it was supported by further clinical investigations reporting the association between iron overload and bone disorders, including osteomalacia (8), osteoporosis (9), altered microarchitecture (10) and bone fractures (11). Despite this, no direct clinical evidence has been established until now regarding the concentration of hepcidin, a key regulator in homeostasis of iron, as well as the iron concentration in the peripheral sera of patients with OP.

Hepcidin, also LEAP-1 (12), HEPC (13) or HAMP (14), was originally discovered to be involved in the maintenance of iron homeostasis, which is necessary for the regulation of iron storage and iron absorption (15). Any mutation in this gene was found to be able to cause hemochromatosis (16). Hepcidin has been suggested to have anti-osteoporosis effects by preventing iron overload (17), suggesting that the level of hepcidin seems to be inversed with level of iron accumulation. Sun et al (18) confirmed the in vivo use of a transgenic mouse model. In addition, the relevant studies performed concerning hepcidin in osteoporosis were either from in vitro cell culture system or in vivo animal models. Clinical status of hepcidin remains to be investigated in patients with OP.

In order to understand the status of hepcidin, soluble TFR 2 as well as the iron concentration in the sera of patients with OP, we detected the concentration of hepcidin, soluble TFR2 and iron in sera based on biochemical autoanalyzer (Cobas 8000; Roche Diagnostics, Indianapolis, IN, USA). It was demonstrated that iron concentration and soluble TFR2 were significantly higher 
in the sera of patients with OP than that of healthy control and that concentration of hepcidin was pronouncedly lower in OP than that in control. To further explore the biochemical role of hepcidin, we showed that hepcidin can interact with TFR2 using immunoprecipitation method.

The present study is the first to establish the direct clinical evidence for hepcidin and iron overload in OP, suggesting that upregulation of hepcidin could be used as an alternative therapeutic strategy in the management of OP.

\section{Materials and methods}

Clinical serum samples. The present study was approved by the Medical Ethics Committee of Qilu Hospital of Shandong University (Qingdao, China). Written informed consent was obtained from each participant involved in the study. Forty serum samples from patients with OP were collected from the Department of Nuclear Medicine, The Affiliated Hospital of Qingdao University. As healthy control, 40 serum samples were collected from the Department of Laboratory Medicine, Qilu Hospital of Shandong University (Qingdao).

Biochemical analysis of hepcidin and iron in sera. The concentration of iron in sera from OP group and healthy control group was measured by Cobas 8000 model Roche autoanalyser (Cobas 8000; Roche Diagnostics ). Given that the preproprotein of hepcidin was post-translationally cleaved into mature peptides of 20, 22 and 25 amino acids, here we focused only on hepcidin 25 . Serum hepcidin 25 (bioactive) was measured by enzyme-linked immunosorbent assay (ELISA) (cat. no. EIA-5782; DRG International, Inc., Springfield Township, NJ, USA). In a similar way, soluble TFR2 was also measured using ELISA kit (cat. no. E-EL-H2346; Biofavor Biotech, Inc., Wuhan, China).

293 T cell culture and transfection constructs. 293T cells were maintained at $37^{\circ} \mathrm{C}$ in Dulbecco's modified Eagle's medium (DMEM) supplemented with $10 \%$ fetal bovine serum (FBS), $100 \mathrm{U} / \mathrm{ml}$ penicillin and $100 \mu \mathrm{g} / \mathrm{ml}$ streptomycin (Gibco, Carlsbad, CA, USA). Cells were transiently transfected with plasmid DNA by Lipofectamine 2000 (Invitrogen), unless otherwise specified. For Lipofectamine transfection, cells were transfected with 2-8 $\mu \mathrm{g}$ plasmid DNA in Opti-MEM I reduced serum media (Invitrogen, Carlsbad, CA, USA) containing Lipofectamine 2000 at a ratio of $1 \mu \mathrm{g}$ DNA to $2 \mu \mathrm{l}$ Lipofectamine for $5 \mathrm{~h}$ before replacing the media with DMEM. Cells were allowed to incubate for $24 \mathrm{~h}$ before being harvested. The expression plasmids used are described below: Eukaryotic expression vector harboring human transferrin receptor 2 (TFR2) gene tagged with Myc-DDK (cat. no. RC220060; and the vector harboring human hepcidin gene tagged with GFP (cat. no. RG204620 were commercially available from Origene Technologies, Inc., Rockville, MD, USA).

Immunoprecipitation (IP). The two vectors were co-transfected into HEK293T cells, followed by collection with SDS protein lysis buffer. The lysates were centrifuged at $12,000 \mathrm{x} \mathrm{g}$ for $10 \mathrm{~min}$ at $4^{\circ} \mathrm{C}$ and the resulting supernatant diluted 5-fold with IP buffer (50 nM Tris-HCI, pH 7.5, $150 \mathrm{nM} \mathrm{NaCl}$, 2 mM EDTA, $1 \%$ NP-40 and 10 mM N-ethylmaleimide).
Table I. Baseline characteristics of the patient with OP and healthy controls.

\begin{tabular}{lccc}
\hline Variable & $\begin{array}{c}\text { OP group } \\
(\mathrm{n}=40)\end{array}$ & $\begin{array}{c}\text { Healthy control } \\
(\mathrm{n}=40)\end{array}$ & P-value \\
\hline Age (years) & $51.22 \pm 7.38$ & $50.45 \pm 10.02$ & 0.538 \\
Sex $(\mathrm{F} / \mathrm{M})$ & $29 / 11$ & $26 / 14$ & 0.782 \\
BMI $\left(\mathrm{kg} / \mathrm{m}^{2}\right)$ & $32.16 \pm 6.63$ & $31.06 \pm 3.87$ & 0.314 \\
Iron $(\mu \mathrm{m} / \mathrm{ml})$ & $18.57 \pm 3.36$ & $9.34 \pm 3.15$ & 0.012 \\
Hepcidin $(\mathrm{ng} / \mathrm{ml})$ & $11.48 \pm 4.12$ & $29.88 \pm 4.23$ & 0.019 \\
TFR2 $(\mathrm{ng} / \mathrm{ml})$ & $19.31 \pm 3.41$ & $8.70 \pm 3.26$ & 0.022 \\
\hline
\end{tabular}

Normally distributed variables are expressed as mean \pm standard error of mean (SEM) and non-normally distributed variables are presented as median. F, female; $\mathrm{M}$, male.

The lysates were pre-cleared by incubating with rabbit sera for $30 \mathrm{~min}$ followed by incubation with protein A-Sepharose beads (GE Healthcare) for $1 \mathrm{~h}$. The lysates were recovered by centrifugation at $12,000 \mathrm{xg}$ for $10 \mathrm{~min}$ at $4^{\circ} \mathrm{C}$ after which the supernatant was moved to a fresh tube. The supernatant was incubated with $10 \mu \mathrm{l}$ of rabbit monoantibody to hepcidin for $1.5 \mathrm{~h}$ followed by protein A-Sepharose beads for another $1.5 \mathrm{~h}$. The incubation was performed at $4{ }^{\circ} \mathrm{C}$ with gentle rotation. The beads were recovered by centrifugation and washed 4 times with IP buffer. The proteins were eluted from the beads by incubation with sample loading buffer at $37^{\circ} \mathrm{C}$ for $10 \mathrm{~min}$. Equal volumes of supernatant were separated on SDS-PAGE and the precipitated proteins detected by immunoblotting (IB). Rabbit mono-antibodies to human hepcidin (cat. no. ab187778), TFR2 (cat. no. ab185550) and IgG (cat. no. ab218427) were all obtained commercially from Abcam (Cambridge, MA, USA).

Statistical analysis. Statistical analyses were carried out using SPSS 17.0 version (SPSS, Inc., Chicago, IL, USA). Continuous variables are expressed as the mean \pm standard error of mean (SEM). Normality of the distribution was assessed with the Kolmogorov-Smirnov test. The differences between groups in terms of numerical variables were examined using the independent sample t-test or the Mann-Whitney U test, according to the provided condition of parametric or non-parametric distribution. Pearson's correlation analysis was performed to evaluate the relationship between numeric variables. $\mathrm{P}<0.05$ was considered to be statistically significant.

\section{Results}

Baseline characteristics. Baseline characteristics of the patient and control groups are shown in Table I. There were no differences in age, sex and BMI between the two groups. Nevertheless, there was a significant difference of iron, hepcidin and TFR 2 concentration between the two groups. Iron concentration was presented to be markedly higher in the sera of OP group $(18.57 \pm 3.36 \mu \mathrm{M} / \mathrm{ml})$ than that of healthy control group $(9.34 \pm 3.15 \mu \mathrm{M} / \mathrm{ml})$, as exemplified by Roche biochemical autoanalyzer. Similarly, the concentration of soluble TFR2 was also significantly elevated in OP $(19.31 \pm 3.41 \mathrm{ng} / \mathrm{ml})$ than 
Table II. The correlation between hepcidin and TRF2.

\begin{tabular}{lcc}
\hline & \multicolumn{2}{c}{$\operatorname{Hepcidin}(\mathrm{ng} / \mathrm{ml})$} \\
\cline { 2 - 3 } Variable & $\mathrm{r}$ & P-value \\
\hline Age (years) & 0.525 & 0.056 \\
BMI $\left(\mathrm{kg} / \mathrm{m}^{2}\right)$ & 0.071 & 0.612 \\
Iron $(\mu \mathrm{M} / \mathrm{ml})$ & -0.031 & 0.021 \\
Hepcidin $(\mathrm{ng} / \mathrm{ml})$ & - & - \\
TFR2 $(\mathrm{ng} / \mathrm{ml})$ & -0.258 & 0.038 \\
\hline
\end{tabular}
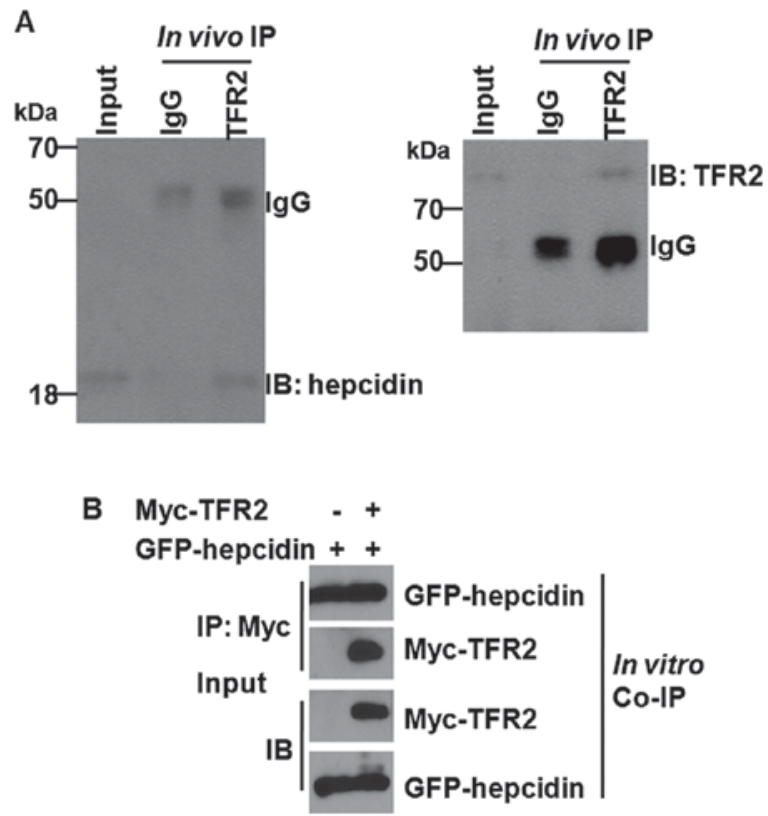

Figure 1. Hepcidin interacts directly with TFR2. (A) Co-Immunoprecipitation (Co-IP) was carried out in vivo in lysates of 293T cells with specific monoantibody to TFR2 and hepcidin. Rabbit anti-human IgG was used as control. (B) Co-IP was performed in lysates of 293T cells after cotransfection with eukaryotic expression vectors harboring GFP-hepcidin and Myc-TFR2. The molecular weight (MW) of endogenous human hepcidin and TRF2 were $\sim 25$ and $88 \mathrm{kDa}$, respectively. Accordingly, the final MW of hepcidin fused with GFP and TRF2 tagged with Myc were 55 and $90 \mathrm{kDa}$, respectively. Representative figure selected among the three independent experiments.

that $(8.70 \pm 3.26 \mathrm{ng} / \mathrm{ml})$ in healthy control. By contrast, the concentration of hepcidin was shown to be remarkably lower in sera of OP $(11.48 \pm 4.12 \mathrm{ng} / \mathrm{ml})$ than that $(29.88 \pm 4.23 \mathrm{ng} / \mathrm{ml})$ of healthy control. To observe whether there was a significant correlation between soluble TRF2 and hepcidin, Pearson's correlation analysis was performed. It indicated that there was a significant negative correlation between soluble TRF2 vs. hepcidin (Table II).

Hepcidin can interplay with TFR2. Having identified a significant correlation between soluble TRF2 and hepcidin, we determined whether there is a direct interaction between hepcidin and TFR2. To approach the problem, we conducted the IP in vivo. To ensure that our IP contained only hepcidin and TFR2 proteins and were devoid of its associated proteins, the IP was carried out in the presence of SDS to break up any potential protein complex. As shown in Fig. 1A, the specific monoantibody to TFR2 immunoprecipitated the TFR2 and hepcidin proteins successfully. The specificity of the IP was evident from the failure of the pre-immune IgG to immunnoprecipitate the hepcidin protein. The signal of the bands was actually faint, at least not as significant as the brightness of $\mathrm{IgG}$, which was used as control. For further verification, the Co-IP was performed in vitro using co-transfection of eukaryotic expression vectors of hepcidin and TFR2 into 293T cells (Fig. 1B). As expected, in vitro Co-IP result confirmed that hepcidin can interplay with TFR2, with the signal of band being strong. The results demonstrated that hepcidin can interplay with TFR2.

\section{Discussion}

To the best of our knowledge, this is the first study on hepcidin and TFR2 expression in sera of OP. Hepcidin was significantly reduced in the sera of patients with OP compared with healthy controls, whereas the iron concentration and soluble TFR2 was pronouncedly elevated in the sera of osteoporosis relative to healthy control. We also report that hepcidin can interplay with TFR2 in a protein-protein interaction fashion. These results present the biochemical profiles of hepcidin and TFR2 expression in sera of OP, which may account for the clinical phenotype that elevated iron concentration was observed in the sera of patients with OP.

Hepcidin is a protein that in humans is encoded by the HAMP gene, which is a key regulator of the entry of iron into the circulation in mammals (15). Hepcidin inhibits iron transport by binding to the iron export channel ferroportin that is located on the basolateral surface of gut enterocytes and the plasma membrane of reticuloendothelial cells $(19,20)$. The first direct experimental evidence establishing the linkage between hepcidin and OP came from the study performed by $\mathrm{Xu}$ and colleagues (17) reporting that hepcidin was shown to be significantly capable of increasing intracellular calcium concentration in osteoblast cell line hFOB1.19. The study, albeit carried out in an in vitro cell culture system, sheds new light into the crucial role of iron homeostasis in bone metabolism (5). Abnormal calcium metabolism has been traditionally taken to be associated with the development of OP (5). Nevertheless, only abnormal calcium metabolism itself was obviously not sufficient to account for the pathogenesis of OP. Given this, imbalance of iron may be an alternative hypothesis explaining the etiology of OP. The present study, therefore, was important in disclosing the imbalance of iron in OP. We demonstrated using ELISA that hepcidin was markedly lower in the sera of OP than that of healthy control, which was basically in line with observations made by Sun et al (18). Using a murine model where the hepcidin gene was double knocked out the study by Sun et al (18) identified that, hepcidin deficiency resulted in a marked reduction of bone load-bearing ability, indicating a link between hepcidin deficiency and bone loss. Considering the biochemical role of hepcidin (20), reduced level of hepcidin can lead to the accumulation of iron, as we observed by Roche biochemical autoanalyzer, which was supported by earlier several lines of evidence $(9,21)$. However, the manner of hepcidin down-regulation in OP remains unknown and deserves further investigation. 
It has been well-established that hepcidin inhibited iron transport through binding to ferroportin $(19,20)$. However, the interaction between hepcidin and transferrin receptor 2 (TFR2) remains to be elucidated as no direct evidence has been established concerning the interaction between hepcidin and TFR2, although association studies have suggested that there was a negative correlation between them in the context of anemia (22) and in children with vegetarian diet (23). In the present study, we showed using ELISA approach that soluble TFR2 was also significantly higher in the sera of OP than that of healthy controls. In the case of concentration trend of hepcidin and TFR2 in sera, our observation was in total agreement with previous reports performed in the setting of anemia (22) and vegetarian (23). In addition, we have shown for the first time, to the best of our knowledge, that hepcidin can directly interact with TFR2, which could explain the reason for hepcidin being detected to be lower in sera of OP relative to healthy control.

There were some limitations that deserve to be noted. Firstly, our conclusion was established on the limited number of sample that requires to be further confirmed in larger sample size. Secondly, direct extrapolation of our conclusion from the study should be approached with caution in that, a higher concentration of iron detected in serum relative to normal range or control does not necessarily mean the onset of OP. It may also be associated with anemia and hemochromatosis, therefore a high concentration of iron in sera seems to be sufficiently necessary but insufficient condition to the judgment of onset of OP. Thirdly, hepcidin has been shown to be able to increase the intracellular calcium (17), the calcium concentration should have been detected.

In conclusion, the present study supports the role of hepcidin in the development of OP, suggesting that upregulation of hepcidin could be used as a novel alternative therapeutic strategy in the management of OP.

\section{Acknowledgements}

The present study was supported by the Department of Laboratory Medicine, Qilu Hospital of Shandong University (Qingdao, China).

\section{Funding}

This research did not receive any specific grant from funding agencies in the public, commercial, or not-for-profit sectors.

\section{Availability of data and material}

The datasets used and/or analyzed during the present study are available from the corresponding author on reasonable request.

\section{Authors' contributions}

BL and CL contributed to the conception of the study. WZ contributed significantly to the data analysis and study preparation. MS and SD performed the data analyses and wrote the study. JS helped perform the data analysis with constructive discussions. All authors have read and approved the final study.

\section{Ethics approval and consent to participate}

The present study was approved by the Medical Ethics Committee of Qilu Hospital of Shandong University (Qingdao, China). Written informed consent was obtained from each participant involved in the study.

\section{Patient consent for publication}

Not applicable.

\section{Competing interests}

The authors declare that they have no competing interests.

\section{References}

1. Qu B, Ma Y, Yan M, Wu HH, Fan L, Liao DF, Pan XM and Hong Z: The economic burden of fracture patients with osteoporosis in western China. Osteoporos Int 25: 1853-1860, 2014.

2. Hendrickx G, Boudin E and Van Hul W: A look behind the scenes: The risk and pathogenesis of primary osteoporosis. Nat Rev Rheumatol 11: 462-474, 2015.

3. Ochoa-Hortal Rull MA, Cano-García MC, Arrabal-Martín M and Arrabal-Polo MA: Lithogenic factors in postmenopausal women with osteoporotic fracture. Minerva Endocrinol 42: 41-45, 2017.

4. Rull MA, Cano-García MC, Arrabal-Martín M and ArrabalPolo MA: The importance of urinary calcium in postmenopausal women with osteoporotic fracture. Can Urol Assoc J 9: E183-E186, 2015.

5. Li GF, Pan YZ, Sirois $\mathrm{P}, \mathrm{Li} \mathrm{K}$ and $\mathrm{Xu} \mathrm{YJ}$ : Iron homeostasis in osteoporosis and its clinical implications. Osteoporos Int 23: 2403-2408, 2012.

6. Tian Q, Wu S, Dai Z, Yang J, Zheng J, Zheng Q and Liu Y: Iron overload induced death of osteoblasts in vitro: Involvement of the mitochondrial apoptotic pathway. PeerJ 4: e2611, 2016.

7. Sinigaglia L, Fargion S, Fracanzani AL, Binelli L, Battafarano N, Varenna M, Piperno A and Fiorelli G: Bone and joint involvement in genetic hemochromatosis: Role of cirrhosis and iron overload. J Rheumatol 24: 1809-1813, 1997.

8. Mahachoklertwattana P, Sirikulchayanonta V, Chuansumrit A, Karnsombat P, Choubtum L, Sriphrapradang A, Domrongkitchaiporn S, Sirisriro R and Rajatanavin R: Bone histomorphometry in children and adolescents with betathalassemia disease: Iron-associated focal osteomalacia. J Clin Endocrinol Metab 88: 3966-3972, 2003.

9. Valenti L, Varenna M, Fracanzani AL, Rossi V, Fargion S and Sinigaglia L: Association between iron overload and osteoporosis in patients with hereditary hemochromatosis. Osteoporos Int 20: 549-555, 2009.

10. Tsay J, Yang Z, Ross FP, Cunningham-Rundles S, Lin H, Coleman R, Mayer-Kuckuk P, Doty SB, Grady RW, Giardina PJ, et al: Bone loss caused by iron overload in a murine model: Importance of oxidative stress. Blood 116: 2582-2589, 2010.

11. Chen B, Li GF, Shen Y, Huang XI and Xu YJ: Reducing iron accumulation: A potential approach for the prevention and treatment of postmenopausal osteoporosis. Exp Ther Med 10: 7-11, 2015.

12. Krause A, Neitz S, Mägert HJ, Schulz A, Forssmann WG, Schulz-Knappe P and Adermann K: LEAP-1, a novel highly disulfide-bonded human peptide, exhibits antimicrobial activity. FEBS Lett 480: 147-150, 2000.

13. Pigeon C, Ilyin G, Courselaud B, Leroyer P, Turlin B, Brissot P and Loréal O: A new mouse liver-specific gene, encoding a protein homologous to human antimicrobial peptide hepcidin, is overexpressed during iron overload. J Biol Chem 276: 7811-7819, 2001.

14. Truksa J, Gelbart T, Peng H, Beutler E, Beutler B and Lee P: Suppression of the hepcidin-encoding gene Hamp permits iron overload in mice lacking both hemojuvelin and matriptase-2/ TMPRSS6. Br J Haematol 147: 571-581, 2009.

15. Ganz T: Hepcidin, a key regulator of iron metabolism and mediator of anemia of inflammation. Blood 102: 783-788, 2003. 
16. Beaumont-Epinette MP, Delobel JB, Ropert M, Deugnier Y, Loréal O, Jouanolle AM, Brissot P and Bardou-Jacquet E: Hereditary hypotransferrinemia can lead to elevated transferrin saturation and, when associated to HFE or HAMP mutations, to iron overload. Blood Cells Mol Dis 54: 151-154, 2015.

17. Xu Y, Li G, Du B, Zhang P, Xiao L, Sirois P and Li K: Hepcidin increases intracellular $\mathrm{Ca}^{2+}$ of osteoblast hFOB1.19 through L-type $\mathrm{Ca}^{2+}$ channels. Regul Pept 172: 58-61, 2011.

18. Sun L, Guo W, Yin C, Zhang S, Qu G, Hou Y, Rong H, Ji H and Liu S: Hepcidin deficiency undermines bone load-bearing capacity through inducing iron overload. Gene 543: 161-165, 2014.

19. Gulec S, Anderson GJ and Collins JF: Mechanistic and regulatory aspects of intestinal iron absorption. Am J Physiol Gastrointest Liver Physiol 307: G397-G409, 2014.

20. Rossi E: Hepcidin - the iron regulatory hormone. Clin Biochem Rev 26: 47-49, 2005

21. Rossi F, Perrotta S, Bellini G, Luongo L, Tortora C, Siniscalco D Francese M, Torella M, Nobili B, Di Marzo V, et al: Iron overload causes osteoporosis in thalassemia major patients through interaction with transient receptor potential vanilloid type 1 (TRPV1) channels. Haematologica 99: 1876-1884, 2014.
22. Choi HS, Song SH, Lee JH, Kim HJ and Yang HR: Serum hepcidin levels and iron parameters in children with iron deficiency. Korean J Hematol 47: 286-292, 2012.

23. Ambroszkiewicz J, Klemarczyk W, Mazur J, Gajewska J, Rowicka G, Strucińska M and Chełchowska M: Serum hepcidin and soluble transferrin receptor in the assessment of iron metabolism in children on a vegetarian diet. Biol Trace Elem Res 180: 182-190, 2017.

(i) (9) This work is licensed under a Creative Commons Attribution-NonCommercial-NoDerivatives 4.0 International (CC BY-NC-ND 4.0) License. 